\title{
Intramucosal esophageal adenocarcinoma: Primum non nocere
}

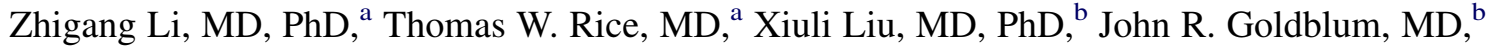 \\ Sarah J. Williams, MS, ${ }^{\mathrm{c}}$ Lisa A. Rybicki, MS, ${ }^{\mathrm{c}}$ Sudish C. Murthy, MD, PhD, ${ }^{\mathrm{a}}$ David P. Mason, MD, ${ }^{\mathrm{a}}$ \\ Daniel P. Raymond, MD, and Eugene H. Blackstone, MD $^{\mathrm{a}, \mathrm{c}}$
}

Objectives: Intramucosal esophageal cancer treatment is evolving. Less-invasive therapies have emerged, necessitating review of safety, effectiveness, and determinants of long-term outcome after esophagectomy to clarify the role of this traditional, maximally invasive, and potentially harmful therapy.

Methods: From January 1983 to January 2011, 164 patients underwent esophagectomy alone for intramucosal adenocarcinoma. Cancers were subdivided by depth of invasion: lamina propria $50(30 \%)$ and muscularis mucosa $114(70 \%$; inner 42 [26\%], middle $16[10 \%]$, and outer $56[34 \%])$. We assessed complications and esophagectomy-related mortality (safety) and cancer recurrence (effectiveness), and identified determinants of long-term outcomes.

Results: Barrett esophagus $(P=.005)$, larger cancers $(P<.001)$, worse histologic grade $(P<.001)$, lymphovascular invasion $(P<.001)$, and overstaging $(P=.02)$ were associated with deeper cancers. One patient had regional lymph node metastases $(0.6 \%)$. Seventy-five patients $(46 \%)$ had complications. Seven of 9 deaths within 6 months were esophagectomy related, 6 from respiratory failure. Seven patients had recurrence, all within 4 years. Five-, 10-, and 15-year survivals were $82 \%, 69 \%$, and $60 \%$, respectively, which were similar to those of a matched general population. Determinants of late mortality were older age $(P=.004)$, poorer lung function $(P<.0001)$, longer cancer $(P=.04)$, postoperative pneumonia $(P=.06)$, cancer recurrence $(P<.0001)$, and second cancers $(P<.0001)$.

Conclusions: Survival after esophagectomy for intramucosal adenocarcinoma is excellent, determined more by patient than cancer characteristics. Patient selection and respiratory function are crucial to minimize harm. Considering the outcome of emerging therapies, esophagectomy should be reserved for patients with a long intramucosal adenocarcinoma or those in whom endoscopic therapies fail or are inappropriate. (J Thorac Cardiovasc Surg 2013;145:1519-24)

Supplemental material is available online.

Intramucosal esophageal adenocarcinoma treatment is evolving. Less invasive therapies have emerged, necessitating reexamination of esophagectomy. To clarify the role of this traditional, maximally invasive, and potentially harmful procedure, we assessed its safety and effectiveness, and

\footnotetext{
From the Department of Thoracic and Cardiovascular Surgery, ${ }^{\mathrm{a}}$ Heart and Vascular Institute, Department of Anatomic Pathology, ${ }^{\mathrm{b}}$ Pathology and Laboratory Medicine Institute, and Department of Quantitative Health Sciences, ${ }^{c}$ Research Institute, Cleveland Clinic, Cleveland, Ohio.

Funding: This research was supported in part by the Daniel and Karen Lee Endowed Chair in Thoracic Surgery (held by Dr Rice), and the Kenneth Gee and Paula Shaw, $\mathrm{PhD}$, Chair in Heart Research (held by Dr Blackstone).

Disclosures: Authors have nothing to disclose with regard to commercial support.

Zhigang Li is the 2011-2012 Evarts Graham Traveling Fellow.

Received for publication July 23, 2012; accepted for publication Oct 16, 2012; available ahead of print Nov 16, 2012.

Address for reprints: Thomas W. Rice, MD, Department of Thoracic and Cardiovascular Surgery, Cleveland Clinic, 9500 Euclid Ave/Desk J4-1, Cleveland, OH 44195 (E-mail: ricet@ccf.org).

$0022-5223 / \$ 36.00$

Copyright (c) 2013 by The American Association for Thoracic Surgery

http://dx.doi.org/10.1016/j.jtcvs.2012.10.027
}

identified patient and cancer determinants of long-term outcome.

\section{PATIENTS AND METHODS \\ Patients}

From January 1983 to January 2011, 1357 patients underwent esophagectomy for cancer at Cleveland Clinic (Appendix E1). Of these patients, 164 had a pathologic diagnosis of adenocarcinoma invading the mucosae but not beyond (pT1a). All patients had esophagectomy alone without induction therapy. The esophagectomy database used for this study was approved for use in research by the institutional review board, with patient consent waived.

Patients were predominantly elderly white men with hiatal hernia (87\%) and Barrett esophagus (92\%) (Table 1); 38\% were in a Barrett surveillance program. Lung function varied widely, and $13 \%$ of patients had a prior nonesophageal malignancy.

\section{Cancer Characteristics}

Clinical stage was determined by biopsy at esophagogastroduodenoscopy in 164 patients, with additional esophageal ultrasound staging in 88 patients $(54 \%)$. Clinical stage was clinical high-grade dysplasia (HGD) in 28 patients $(17 \%)$, cT1aN0 in 115 patients $(70 \%)$, and greater than cT1N0 in 21 patients (13\%) (Table 1). Ninety-eight percent of cancers $(\mathrm{n}=161)$ were located in the lower thoracic esophagus. Cancers were small, with a median length at esophagogastroduodenoscopy of $0.8 \mathrm{~cm}$ and width of $0.4 \mathrm{~cm}$. Pathologic re-review was performed by 2 


\section{Abbreviation and Acronym \\ HGD $=$ high-grade dysplasia}

gastrointestinal pathologists. Cancer length, depth of invasion, histologic grade, presence of lymphovascular invasion, and number of positive nodes were assessed. One patient was found to have 6 positive nodes (pN2). However, $14 \%$ of patients had definite or possible lymphovascular invasion. No patient had distant metastasis. The majority of cancers were moderate or well differentiated $(85 \%)$.

\section{Esophagectomy}

Sixty-eight percent of patients $(n=111)$ underwent a transhiatal esophagectomy, and $32 \%$ underwent a thoracotomy. ${ }^{1}$ All cancer margins were R0, except in 1 patient who had Barrett esophagus without dysplasia at the proximal margin. The median number of lymph nodes sampled was 12 .

\section{Outcomes}

Safety was assessed by the combination of postoperative complications (Table 2), operative mortality (deaths in hospital or within 30 days of esophagectomy), and deaths in the first 6 months attributed to esophagectomy (esophagectomy related). Effectiveness was assessed by esophageal cancer recurrence and all-cause mortality referenced to an age-, race-, and sex-matched US population. Determinants of long-term outcome were based on cancer recurrence, all-cause mortality, and second nonesophageal cancer.

Active follow-up for vital status, cancer recurrence, and second cancers was complete to January 2010 in 156 patients (95\%) and to January 2011 in 104 patients $(63 \%)$. Median follow-up was 85 months, and $10 \%$ of patients were followed more than 14 years. For survival, time relatedness of cancer recurrence, all-cause mortality, and second cancers were estimated by the nonparametric time-related Kaplan-Meier method and parametrically using multiphase hazard modeling. ${ }^{2}$ (For additional details, see http://my. clevelandclinic.org/professionals/software/hazard/default.aspx.) Overall survival was referenced to an age-, race-, and sex-specific US population.

Determinants of long-term outcomes were identified for cancer recurrence, all-cause mortality, and second cancers, and for each hazard phase simultaneously using variables listed in Table 1 and detailed in Appendix E2. Variable selection used bagging. ${ }^{3,4}$ Briefly, automated stepwise variable selection was performed on 1000 bootstrap samples, and frequency of occurrence of variables related to procedure performed was ascertained by the median rule. ${ }^{3}$ For all-cause mortality, analysis proceeded sequentially. First, only preoperative patient and cancer characteristics were entered into the analysis. This was followed by these plus details of the operation and then of postoperative complications. Finally, esophageal cancer recurrence and second cancer, and time to their diagnosis, were entered as time-varying covariables.

\section{Presentation}

Continuous variables are summarized as mean \pm 1 standard deviation for normally distributed variables and as equivalent median, 15th, and 85 th percentiles when values are skewed. Categoric variables are summarized as frequency and percentage. Time-related estimates are accompanied by $68 \%$ confidence limits equivalent to \pm 1 standard error.

\section{RESULTS}

\section{Safety}

Mortality. Three patients $(1.8 \%)$ died in hospital, and 2 patients $(1.2 \%)$ died within 30 days of esophagectomy. Nine deaths occurred within 6 months, 7 of which were esophagectomy related, resulting in an actuarial survival of $95 \%$ at 6 months. These deaths were from respiratory failure in 6 patients and accompanied by renal failure in 3 . The seventh patient died of superior mesenteric artery thrombosis.

Complications. Seventy-five patients $(46 \%)$ experienced 125 complications (Table 3 ). The most common were wound $(22 \%)$, cardiovascular $(21 \%)$, and respiratory $(20 \%)$.

\section{Effectiveness}

Cancer recurrence. Seven patients had esophageal cancer recurrence, all within 4 years of esophagectomy (Figure 1), 3 locoregional and 4 distant. One patient is alive 43 months after esophagectomy, and 6 patients died 13 to 58 months after esophagectomy (4-44 months after recurrence).

All-cause mortality. Five-, 10-, and 15-year survivals were $82 \%, 69 \%$, and $60 \%$, respectively (Figure 2 ). These cancer patients had a higher risk of death after esophagectomy than a matched US population (Figure 2), but after 9 months, risk was similar.

\section{Determinants of Long-Term Outcome}

Preoperative. No predictors of early mortality were identified because of the small number of postoperative events. Operative mortality was similar across the experience. Patient characteristics associated with mortality included older age at esophagectomy and poorer lung function (Table 4 and Figure E1). The only cancer characteristic associated with mortality was length. However, there was interplay among cancer characteristics. Barrett esophagus, deeper invasion of the mucosa, worse histologic grade, lymphovascular invasion, and overstaging were associated with larger cancers (Table E1 and Figure E2).

Operative details. No operative feature was a risk factor. Postoperative. Respiratory complications, particularly pneumonia, increased the risk of mortality (Table 4).

Time-related factors. Cancer recurrence and second nonesophageal cancers (Figure 3) were risk factors for late mortality (Table 4). The following cancers developed in 20 patients: 23 second nonesophageal malignancies, 10 genitourinary (6 prostate, 3 kidney, 1 bladder), 3 lung, 3 colorectal, 3 skin, and 1 each head and neck, brain, pancreas, and duodenum. Eight patients have died - 6 with second nonesophageal malignancies, 1 with pre-esophagectomy melanoma, and 1 of a non-cancer-related cause.

\section{DISCUSSION}

Intramucosal esophageal adenocarcinoma is truly an early cancer because it is locally confined and rarely metastasizes to lymph nodes. Esophagectomy cures $95 \%$ of patients. However, risk of cancer recurrence is approximately equal to risk of death from esophagectomy. Therefore, it is critical to do no harm in treating patients with this good prognosis, but this maximally invasive procedure 
TABLE 1. Patient and cancer characteristics $(n=164)$

\begin{tabular}{|c|c|c|}
\hline Characteristics & $\mathbf{n}^{*}$ & Value \\
\hline \multicolumn{3}{|l|}{ Patient } \\
\hline Age $(y)$ & 164 & \\
\hline Mean \pm SD & & $63 \pm 10$ \\
\hline Median (range) & & $64(35-82)$ \\
\hline Gender & 164 & \\
\hline Male & & $142(87)$ \\
\hline Female & & $22(13)$ \\
\hline Race & 164 & \\
\hline White & & $161(98)$ \\
\hline Black & & $2(1.2)$ \\
\hline Hispanic & & $1(0.6)$ \\
\hline $\mathrm{FEV}_{1}(\%$ of predicted $)$ & 149 & \\
\hline Mean \pm SD & & $92 \pm 18$ \\
\hline Median (range) & & $92(35-136)$ \\
\hline FVC $(\%$ of predicted $)$ & 148 & \\
\hline Mean \pm SD & & $98 \pm 16$ \\
\hline Median (range) & & $96(57-158)$ \\
\hline Pathologic Barrett esophagus & 164 & \\
\hline Yes & & $151(92)$ \\
\hline No & & $13(7.9)$ \\
\hline Pathologic Barrett length $(\mathrm{cm})$ & 115 & \\
\hline Mean \pm SD & & $4.6 \pm 3.1$ \\
\hline Median (range) & & $4.5(0-12)$ \\
\hline Hiatal hernia & 164 & \\
\hline Yes & & $143(87)$ \\
\hline No & & $21(13)$ \\
\hline Hiatal hernia length $(\mathrm{cm})$ & 164 & \\
\hline Mean \pm SD & & $3.0 \pm 2.0$ \\
\hline Median (range) & & $3.0(0-11)$ \\
\hline \multicolumn{3}{|l|}{ Cancer } \\
\hline Clinical stage $\dagger$ & 164 & \\
\hline cHGD & & $28(17)$ \\
\hline cT1N0 & & $115(70)$ \\
\hline$>\mathrm{cT} 1 \mathrm{~N} 0$ & & $21(13)$ \\
\hline Depth of invasion & 164 & \\
\hline LP & & $50(30)$ \\
\hline MM1 (inner) & & $42(26)$ \\
\hline MM2 (between) & & $16(9.8)$ \\
\hline MM3 (outer) & & $56(34)$ \\
\hline Tumor length on pathology $(\mathrm{cm})$ & 156 & \\
\hline Median (range) & & $0.70(0.10-5.9$ \\
\hline Histologic grade & 164 & \\
\hline G1 & & $55(34)$ \\
\hline G2 & & $83(51)$ \\
\hline G3 & & $26(16)$ \\
\hline Lymphovascular invasion & 154 & \\
\hline Yes & & $6(3.9)$ \\
\hline Possible & & $15(9.7)$ \\
\hline No & & $133(86)$ \\
\hline No. of lymph nodes sampled & 164 & \\
\hline Median (range) & & $12(0-56)$ \\
\hline No. of positive nodes & 164 & \\
\hline 0 & & $163(99)$ \\
\hline 6 & & $1(0.60)$ \\
\hline
\end{tabular}

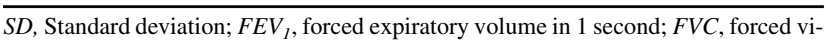
tal capacity; $c H G D$, clinical high-grade dysplasia; $L P$, lamina propria; $M M$, muscularis mucosa. *Patients with data available. $\dagger$ Endoscopic ultrasound and preoperative biopsy.
TABLE 2. Definition of complications

\section{Wound}

Anastomotic leak: Detection of saliva, ingested material, gastric secretions, or bile in the drain or wound. Radiographic confirmation was not required.

Infection: Local findings of erythema, drainage, subcutaneous emphysema, or tenderness requiring wound opening with positive wound culture.

\section{Pulmonary}

Pneumonia: Radiographic confirmation with positive respiratory tract culture.

Respiratory failure: Reintubation or tracheostomy for weaning failure.

Vocal cord paralysis: Laryngoscopy confirmation required.

Pneumothorax: Radiographic confirmation requiring chest tube reinsertion.

Pleural effusion: Pleural effusion after chest tube removal requiring chest tube reinsertion or thoracentesis.

\section{Cardiovascular}

Electrocardiographic confirmation of atrial arrhythmia.

Ultrasound confirmation of deep venous thrombosis.

\section{Neurologic}

Delirium: Transient confusion confirmed by disturbances in consciousness, cognition, and perception.

is associated with postoperative complications in nearly $50 \%$ of patients, and these contribute to the death of $5 \%$ of patients in the first 6 months after surgery. Endoscopic therapy also may do harm because it is not totally safe and is not as effective in curing cancer. This has led us to examine the technical success, safety, and clinical effectiveness of these treatment options.

\section{Success}

Technical success is the ability to locally eliminate cancer and precursor intestinal metaplasia. In this series of 164 patients, all had R0 resections for cancer and $163 \mathrm{had}$ R0 resections for Barrett metaplasia. Intestinal metaplasia

TABLE 3. Postoperative complications

\begin{tabular}{lccc}
\hline \multicolumn{1}{c}{ Type } & $\begin{array}{c}\text { No. of } \\
\text { complications }\end{array}$ & $\begin{array}{c}\text { No. of } \\
\text { patients }\end{array}$ & \% of 164 \\
\hline Wound & 36 & 36 & 22 \\
Anastomotic leak & 9 & 9 & 5.5 \\
Infection & 27 & 27 & 16 \\
Respiratory & 42 & 32 & 20 \\
Pneumonia & 6 & 6 & 3.7 \\
Respiratory failure & 20 & 20 & 12 \\
Vocal cord paralysis & 5 & 5 & 3.0 \\
Pneumothorax & 1 & 1 & 0.6 \\
Pleural effusion & 10 & 10 & 6.1 \\
Cardiovascular & 36 & 35 & 21 \\
Atrial arrhythmia & 26 & & 16 \\
Deep vein thrombosis & 10 & & 6.1 \\
Neurologic & 11 & 11 & 6.7 \\
Delirium & 125 & $75^{*}$ & \\
Total & & & \\
* Many patients had multiple complications. & & & \\
\hline
\end{tabular}

*Many patients had multiple complications. 


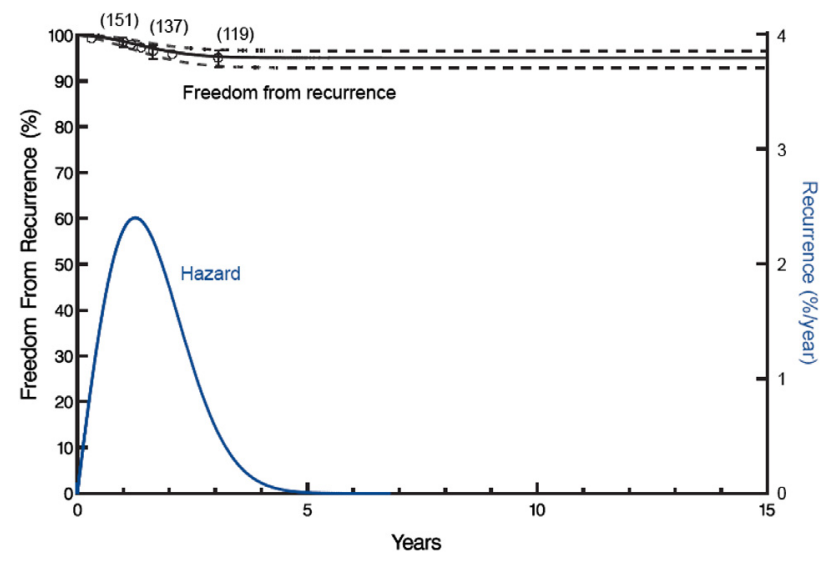

FIGURE 1. Recurrence of cancer after esophagectomy for intramucosal cancer. Each circle represents a recurrence, vertical bars represent $68 \%$ confidence limits, and numbers in parentheses represent patients remaining at risk. Solid line enclosed within dashed $68 \%$ confidence band represents parametric estimate. Instantaneous risk of recurrence (hazard function) peaks at 15 months. There was no recurrence after 37 months.

after a cervical esophagogastrostomy develops in few patients $(16 \%$ at 5 years), and dysplasia and cancer are rare. ${ }^{1}$ Inflammatory changes at the anastomosis can be lessened by construction of a high anastomosis and proton-pump inhibitor therapy.

Endoscopic mucosal resection or ablative therapy is less likely to be technically successful than esophagectomy. In a study by Pech and colleagues ${ }^{5}$ of 486 patients with clinical HGD or intramucosal cancer, 279 underwent endoscopic mucosal resection, 55 received photodynamic ablative therapy, and 13 received both. ${ }^{5}$ Ninety-six percent of patients had a "complete response," but 3.6\% required esophagectomy for technical failures. At a median of 15 months (25th percentile 12 months, 75 th percentile 24 months), $22 \%$ of

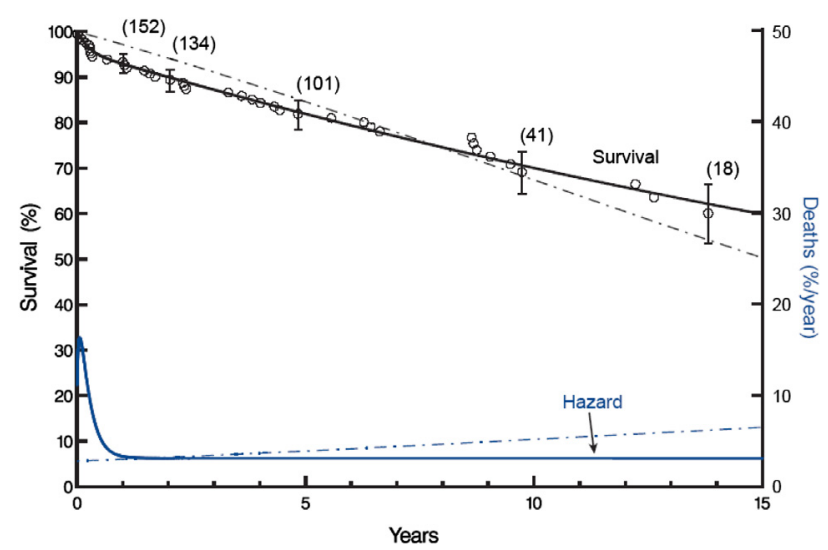

FIGURE 2. Survival after esophagectomy for intramucosal cancer. Format is as in Figure 1 except that the age-, race-, and sex-matched US population life table is superimposed (dash-dot-dash line). Instantaneous risk of death (hazard function) peaks early after operation and then decreases to a constant level similar to that of the general population.
TABLE 4. Incremental risk factors for mortality after esophagectomy for intramucosal cancer: Sequential analysis

\begin{tabular}{|c|c|c|c|}
\hline Risk factor & Coefficient \pm SD & $P$ & $\begin{array}{c}\text { Reliability } \\
(\%)^{*}\end{array}$ \\
\hline \multicolumn{4}{|c|}{ 1. Patient and cancer characteristics, operative details } \\
\hline Older age $(\mathrm{y}) \dagger$ & $0.75 \pm 0.24$ & .002 & 80 \\
\hline $\begin{array}{c}\text { Lower FVC }(\% \text { of } \\
\text { predicted }) \ddagger\end{array}$ & $3.2 \pm 0.52$ & $<.0001$ & 96 \\
\hline Longer cancer $(\mathrm{cm}) \S$ & $0.060 \pm 0.024$ & .01 & 89 \\
\hline \multicolumn{4}{|c|}{ 2. Add postoperative complications } \\
\hline Older age $(\mathrm{y}) \dagger$ & $0.76 \pm 0.24$ & .001 & 76 \\
\hline $\begin{array}{c}\text { Lower FVC }(\% \text { of } \\
\text { predicted }) \ddagger\end{array}$ & $3.3 \pm 0.52$ & $<.0001$ & 94 \\
\hline Longer cancer $(\mathrm{cm}) \S$ & $0.062 \pm 0.023$ & .008 & 88 \\
\hline Postoperative pneumonia & $1.3 \pm 0.67$ & .05 & 55 \\
\hline \multicolumn{4}{|c|}{ 3. Add recurrence and second cancers } \\
\hline Older age $(\mathrm{y}) \dagger$ & $0.58 \pm 0.20$ & .004 & 59 \\
\hline $\begin{array}{c}\text { Lower FVC }(\% \text { of } \\
\text { predicted }) \ddagger\end{array}$ & $3.2 \pm 0.51$ & $<.0001$ & 94 \\
\hline Longer cancer $(\mathrm{cm}) \S$ & $0.051 \pm 0.025$ & .04 & 90 \\
\hline Postoperative pneumonia & $1.1 \pm 0.58$ & .06 & 67 \\
\hline Cancer recurrence & $2.5 \pm 0.46$ & $<.0001$ & 99.6 \\
\hline $\begin{array}{l}\text { Longer interval to second } \\
\text { cancer }(y)\end{array}$ & $0.27 \pm 0.048$ & $<.0001$ & 98.9 \\
\hline
\end{tabular}

No risk factors were identified in the early hazard phase. $S D$, Standard deviation; FVC, forced vital capacity. *Percent of times factor appeared in 1000 bootstrap models. $\dagger$ Exp (age/50), exponential transformation. $\ddagger(81 / \mathrm{FVC})^{2}$, inversed squared transformation. §Length ${ }^{2}$, squared transformation.

patients had HGD or cancer. Predictors of recurrence were piecemeal resection, long-segment Barrett esophagus, no ablative therapy after complete response, more than 10 months required to achieve complete response, and multifocal neoplasia. Among 341 patients studied by Pouw and colleagues, ${ }^{6} 169$ underwent endoscopic resection of early Barrett neoplasia at 4 centers. At the end of treatment, $98 \%$ had eradication of neoplasia and $85 \%$ had eradication of metaplasia. Two patients $(2.4 \%)$ required surgery for immediate technical failures or complications. At a median of 32 months (interquartile range, 19-49 months), 95\% of

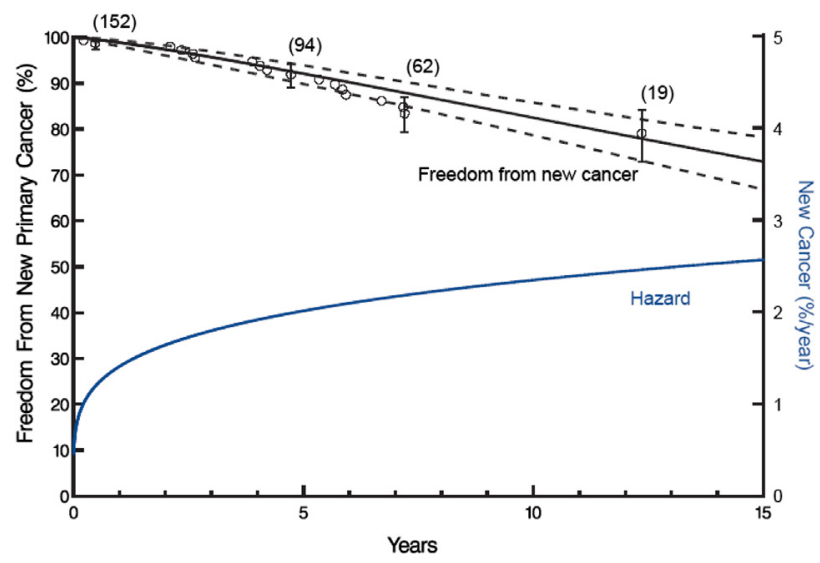

FIGURE 3. Freedom from second nonesophageal cancer after esophagectomy for intramucosal cancer. Depiction is as in Figure 1. 
patients had eradication of neoplasia and $80 \%$ had eradication of metaplasia, with 9 patients $(5.3 \%)$ requiring retreatment during follow-up.

Ablative therapy has been reported typically for Barrett metaplasia and dysplasia but not for intramucosal cancer. Unlike esophagectomy, but like endoscopic resection, ablative therapy is less likely to eradicate Barrett metaplasia and dysplasia. Lyday and colleagues ${ }^{7}$ studied 429 treated patients who had Barrett metaplasia with or without dysplasia. In 1 cohort, 338 patients had at least 1 biopsy session after ablation, with $72 \%$ free of Barrett metaplasia and $89 \%$ free of dysplasia. In another cohort of 137 patients with at least 1 session a year or more after therapy, $77 \%$ were free of metaplasia and $100 \%$ were free of dysplasia. ${ }^{7}$ Among 50 patients with nondysplastic Barrett esophagus reported by Fleischer and colleagues, ${ }^{8}$ freedom from metaplasia after radiofrequency ablation was $91 \%$ (95\% confidence interval, $77 \%-97 \%$ ) at 4 years. Shaheen and colleagues ${ }^{9}$ reported that $77 \%$ of patients had eradication of metaplasia and $81 \%$ had eradication of dysplasia 12 months after ablation of dysplastic Barrett esophagus.

\section{Safety}

Safety is freedom from risk and can be assessed by complications and death after treatment. Although esophagectomy can be performed with a 30-day in-hospital mortality of approximately $1 \%$, longer follow-up demonstrates that it is associated with late death. It can be expected that approximately $50 \%$ of patients will experience a complication after esophagectomy.

Treatment mortality is rarely reported after endoscopic therapy, and complications are less frequent than after esophagectomy by approximately half. ${ }^{10}$ Pech and colleagues $^{5}$ reported complications in $17 \%$ of patients after endoscopic mucosal resection. In other studies, complications occurred in $3.6 \%{ }^{7}$ and $2.3 \%{ }^{9}$ of patients receiving ablation, with strictures reported in $6 \%{ }^{9}$ and $2.1 \%{ }^{7}$

\section{Clinical Effectiveness}

Clinical effectiveness is the ability to cure cancer. Although overall survival is generally similar after esophagectomy or endoscopic therapy, ${ }^{11-13}$ cancer-free survival is worse after endoscopic therapy. Recurrence after esophagectomy is uncommon, and if it occurs, it does so early after surgery, whereas after ablative therapy, recurrence is a later and continuing problem. Prasad and colleagues ${ }^{12}$ reported 5-year cancer-free survival of $97 \%$ after esophagectomy and $80 \%$ after endoscopic therapy $(P=.01)$. Schembre and colleagues ${ }^{13}$ reported no cancer recurrences after a median follow-up of 48 months in 32 patients undergoing esophagectomy, despite identifying previously unrecognized cancer in $25 \%$ of the resection specimens; cancer recurrence developed at a median of 20 months of follow-up in $6 \%$ of 62 patients receiving endoscopic therapy. ${ }^{13}$

\section{Strengths and Limitations}

A limitation of this study is that it is a large, singleinstitution experience covering more than 25 years. However, this is also a strength because of availability of a large volume of long-term data on intramucosal esophageal adenocarcinoma. The patients represent a highly selected referral population. The only outcomes studied were survival, cancer recurrence, and second primary cancer; quality of life was not assessed. This analysis does not include a direct comparison group of patients treated endoscopically.

\section{CONCLUSIONS}

Both esophagectomy and endoscopic therapy may inadvertently harm patients with intramucosal esophageal adenocarcinoma, requiring concerted attempts to improve the safety of both therapies. Esophagectomy is more successful and effective in this setting than endoscopic therapies, but it is not as safe. Treatment decisions require balancing harm with ineffective cancer treatment. It is critical to carefully prescribe therapy on the basis of treatment goals, cancer characteristics, and patient characteristics. Esophagectomy is best for patients in whom complete and durable eradication of the cancer is paramount and in whom esophagectomy is a low-risk procedure. Endoscopic therapy is best for patients in whom the risk of esophagectomy outweighs the need for freedom from cancer. Choice of endoscopic therapy requires adequate esophageal function, that is, is the esophagus worth saving? Choice of esophagectomy requires meticulous patient preparation and fastidious surgical technique. Unfortunately, it has been reported that a major determinant of therapy in patients with these cancers is who performs the first evaluation: a surgeon or a gastroenterologist. ${ }^{14}$

I will prescribe regimens for the good of my patients according to my ability and my judgment and never do harm to anyone.

-Hippocratic Oath

\section{References}

1. Rice TW, Goldblum JR, Rybicki LA, Rajeswaran J, Murthy SC, Mason DP, et al Fate of the esophagogastric anastomosis. J Thorac Cardiovasc Surg. 2011;141: 875-80.

2. Blackstone EH, Naftel DC, Turner ME Jr. The decomposition of time-varying hazard into phases, each incorporating a separate stream of concomitant information. J Am Stat Assoc. 1986;81:615-24.

3. Breiman L. Bagging predictors. Machine Learning. 1996;24:123-40

4. Blackstone EH. Breaking down barriers: helpful breakthrough statistical methods you need to understand better. J Thorac Cardiovasc Surg. 2001;122: 430-9.

5. Pech O, Behrens A, May A, Nachbar L, Gossner L, Rabenstein T, et al. Longterm results and risk factor analysis for recurrence after curative endoscopic therapy in 349 patients with high-grade intraepithelial neoplasia and mucosal adenocarcinoma in Barrett's oesophagus. Gut. 2008;57:1200-6.

6. Pouw RE, Seewald S, Gondrie JJ, Deprez PH, Piessevaux H, Pohl H, et al. Stepwise radical endoscopic resection for eradication of Barrett's oesophagus with early neoplasia in a cohort of 169 patients. Gut. 2010;59:1169-77. 
7. Lyday WD, Corbett FS, Kuperman DA, Kalvaria I, Mavrelis PG, Shughoury AB, et al. Radiofrequency ablation of Barrett's esophagus: outcomes of 429 patients from a multicenter community practice registry. Endoscopy. 2010;42:272-8.

8. Fleischer DE, Overholt BF, Sharma VK, Reymunde A, Kimmey MB, Chuttani R, et al. Endoscopic radiofrequency ablation for Barrett's esophagus: 5-year outcomes from a prospective multicenter trial. Endoscopy. 2010;42:781-9.

9. Shaheen NJ, Sharma P, Overholt BF, Wolfsen HC, Sampliner RE, Wang KK, et al. Radiofrequency ablation in Barrett's esophagus with dysplasia. $N$ Engl J Med. 2009;360:2277-88.

10. Pech O, Bollschweiler E, Manner H, Leers J, Ell C, Holscher AH. Comparison between endoscopic and surgical resection of mucosal esophageal adenocarcinoma in Barrett's esophagus at two high-volume centers. Ann Surg. 2011;254:67-72.
11. Zehetner J, DeMeester SR, Hagen JA, Ayazi S, Augustin F, Lipham JC, et al. Endoscopic resection and ablation versus esophagectomy for high-grade dysplasia and intramucosal adenocarcinoma. J Thorac Cardiovasc Surg. 2011; 141:39-47.

12. Prasad GA, Wu TT, Wigle DA, Buttar NS, Wongkeesong LM, Dunagan KT, et al. Endoscopic and surgical treatment of mucosal (T1a) esophageal adenocarcinoma in Barrett's esophagus. Gastroenterology. 2009;137:815-23.

13. Schembre DB, Huang JL, Lin OS, Cantone N, Low DE. Treatment of Barrett's esophagus with early neoplasia: a comparison of endoscopic therapy and esophagectomy. Gastrointest Endosc. 2008;67:595-601.

14. Yachimski P, Nishioka NS, Richards E, Hur C. Treatment of Barrett's esophagus with high-grade dysplasia or cancer: predictors of surgical versus endoscopic therapy. Clin Gastroenterol Hepatol. 2008;6:1206-11. 

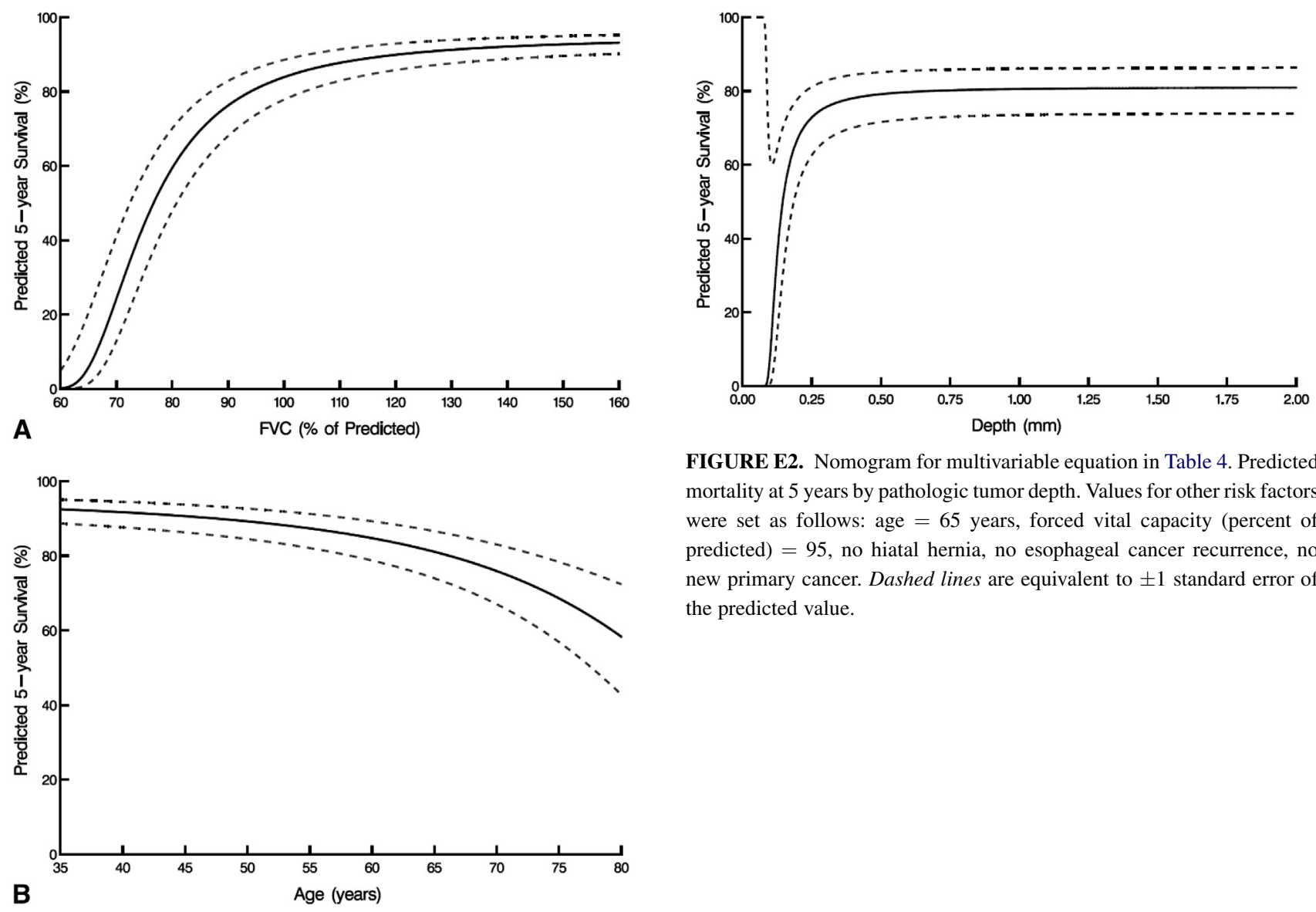

FIGURE E2. Nomogram for multivariable equation in Table 4. Predicted mortality at 5 years by pathologic tumor depth. Values for other risk factors were set as follows: age $=65$ years, forced vital capacity (percent of predicted) $=95$, no hiatal hernia, no esophageal cancer recurrence, no new primary cancer. Dashed lines are equivalent to \pm 1 standard error of the predicted value.

FIGURE E1. Nomogram of 5-year survival after esophagectomy for intramucosal esophageal adenocarcinoma according to lung function and age at operation based on model 1 in Table 4. Dashed lines are equivalent to \pm 1 standard error of the predicted value. A, Lung function. Values for other risk factors were set as follows: age $=65$ years and length of cancer $=1.4 \mathrm{~mm}$. B, Age. Values for other risk factors were set as follows: forced vital capacity (percent of predicted) $=95$ and length of cancer $=1.4$ mm. FVC, Forced vital capacity. 
TABLE E1. Interplay among cancer characteristics

\begin{tabular}{|c|c|c|c|c|c|}
\hline \multirow[b]{2}{*}{ Characteristic } & \multicolumn{4}{|c|}{ Depth of invasion } & \multirow[b]{2}{*}{$P$} \\
\hline & $\begin{array}{c}\mathbf{L P}(\mathbf{n}=\mathbf{5 0}) \\
\text { no. }(\%)\end{array}$ & $\begin{array}{c}\text { MM1 }(n=42) \\
\text { no. }(\%)\end{array}$ & $\begin{array}{c}\text { MM2 }(\mathbf{n}=16) \\
\text { no. }(\%)\end{array}$ & $\begin{array}{c}\text { MM3 }(\mathbf{n}=\mathbf{5 6}) \\
\text { no. }(\%)\end{array}$ & \\
\hline Barrett esophagus & $43(86)$ & $37(88)$ & $15(94)$ & $56(100)$ & .005 \\
\hline \multicolumn{6}{|l|}{ Cancer size on EGD } \\
\hline Length (cm), median (range) & $0.3(0-4.5)$ & $0.4(0-4)$ & $0.8(0-5.5)$ & $1(0-10)$ & .002 \\
\hline Width $(\mathrm{cm})$, median (range)* & $0.3(0-7.5)$ & $0.1(0-7.5)$ & $0.6(0-2.5)$ & $0.6(0-4.6)$ & .01 \\
\hline Area $\left(\mathrm{cm}^{2}\right)$, median (range)* & $0.1(0-30)$ & $0(0-30)$ & $0.4(0-14)$ & $0.5(0-32)$ & .008 \\
\hline \multicolumn{6}{|l|}{ Cancer size on pathology } \\
\hline Length $(\mathrm{cm})$, median (range) $\dagger$ & $0.4(0.1-2.0)$ & $0.7(0.1-2.0)$ & $0.6(0.1-5.5)$ & $1.2(0.3-5.9)$ & $<.001$ \\
\hline Depth $(\mathrm{mm})$, median (range) $\ddagger$ & $0.5(0.2-2.0)$ & $1.0(0.4-4.0)$ & $1.0(0.5-4.5)$ & $1.8(0.1-9.0)$ & $<.001$ \\
\hline Clinical stage & & & & & .02 \\
\hline $\mathrm{cHGD}$ & $12(24)$ & $8(19)$ & $1(6.2)$ & $7(12)$ & \\
\hline $\mathrm{cT} 1$ & $33(66)$ & $31(74)$ & $14(88)$ & $37(66)$ & \\
\hline$>\mathrm{cT} 1$ & $5(10)$ & $3(7.1)$ & $1(6.2)$ & $12(21)$ & \\
\hline Pathologic stage & & & & & $<.001$ \\
\hline IA & $48(96)$ & $38(90)$ & $14(88)$ & $38(68)$ & \\
\hline IB & $2(4.0)$ & $4(9.5)$ & $2(12)$ & $17(30)$ & \\
\hline IIIA & $0(0)$ & $0(0)$ & $0(0)$ & $1(1.8)$ & \\
\hline Histologic grade & & & & & $<.001$ \\
\hline G1 & $24(48)$ & $16(38)$ & $3(19)$ & $12(21)$ & \\
\hline G2 & $24(48)$ & $22(52)$ & $11(69)$ & $26(46)$ & \\
\hline G3 & $2(4.0)$ & $4(9.5)$ & $2(12)$ & $18(32)$ & \\
\hline Lymphovascular invasion & & & & & $<.001$ \\
\hline Yes & $0(0)$ & $0(0)$ & $0(0)$ & $6(11)$ & \\
\hline Possible & $0(0)$ & $3(7.3)$ & $3(19)$ & $9(17)$ & \\
\hline No & $43(100)$ & $38(93)$ & $13(81)$ & $39(72)$ & \\
\hline
\end{tabular}

$L P$, Lamina propria, $M M$, muscularis mucosa; $M M 1$, inner; $M M 2$, between; $M M 3$, outer; $E G D$, esophagogastroduodenoscopy; $c H G D$, clinical high-grade dysplasia. *n $=50,40$, 15 , and 50 , respectively. $\lceil n=43,42,16$, and 55 , respectively. $\ddagger n=42,42,16$, and 55 , respectively.

APPENDIX E1. Clinical and pathologic stage

\begin{tabular}{lcc}
\hline & \multicolumn{2}{c}{ Clinical stage } \\
\cline { 2 - 3 } Pathologic stage & cT1N0* & cT1bxN0 $\dagger$ \\
\hline$<$ pT1N0M0 & 12 & 17 \\
pT1aN0M0 & 65 & 48 \\
pT1aN+M0 $\ddagger$ & 0 & 0 \\
pT1bN0M0 & 43 & 14 \\
pT1bN+M0 & 7 & 3 \\
$>$ pT1N0M0 & 6 & 21 \\
$>$ pT1N+M0 & 4 & 82 \\
$>$ pT1N0M1 & 0 & 1 \\
$>$ pT1N+M1 & 0 & 5 \\
Total & 137 & 191 \\
\hline Of 1357 esophagectomies between January 1983 and January 2010, 1149 were for \\
adenocarcinoma; 722 patients had no induction therapy. Distribution of pathologic \\
stage cT1N0 patients is shown. *cT1 includes both intramucosal (cT1a) and submu- \\
cosal cancers (cT1b). $\dagger$ Endoscopic ultrasound was noninformative, so preoperative \\
biopsy was used to determine clinical stage. $\ddagger$ N + indicates regional lymph node \\
metastases.
\end{tabular}


APPENDIX E2. Variables considered in multivariable analyses

Demographic

Pulmonary function

Esophagus

Cancer

Surgical approach

Postoperative complications

Future complications

Experience
Age (y), sex

$\mathrm{FEV}_{1}$ (percent of predicted), FVC (percent of predicted)

Barrett esophagus, Barrett surveillance, hiatal hernia, hiatal hernia length $(\mathrm{cm})$

Prior cancer; pathologic tumor length (cm), depth (cm), and location (LP, MM1, MM2, MM3); histologic grade (G1, G2, G3); site of anastomosis (neck, chest); pathologic staging (LP, MM1, MM2, MM3, G1, G2, G3); cHGD; total number of nodes sampled

Thoracotomy, transhiatal

Anastomotic leak, respiratory failure, vocal cord paralysis, wound infection, deep vein thrombosis, atrial fibrillation, pleural effusion, pneumothorax, pneumonia

New primary cancer, time to new primary cancer, recurrence of esophageal cancer, time to recurrence of esophageal cancer Years since January 1, 1983

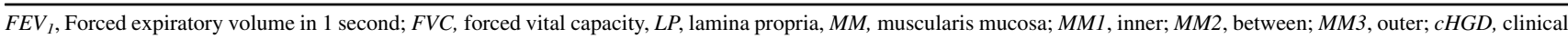
high-grade dysplasia. 